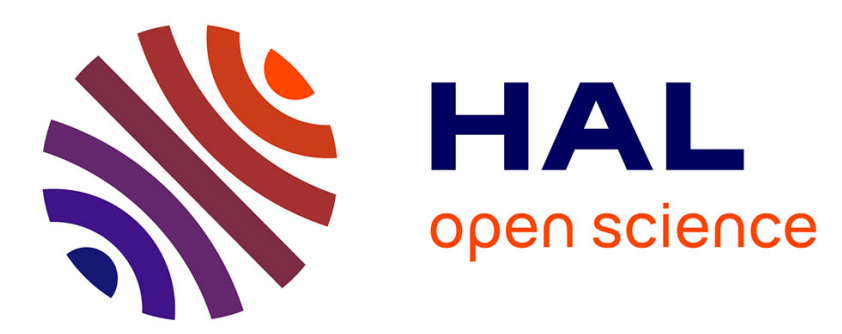

\title{
Substitution and stereochemical effects in the reactions of combined aminonitrile-oxazolidines with a Grignard reagent
}

Joelle Pérard-Viret, Marc Le Bail, David J Aitken, Henri-Philippe Husson

\section{- To cite this version:}

Joelle Pérard-Viret, Marc Le Bail, David J Aitken, Henri-Philippe Husson. Substitution and stereochemical effects in the reactions of combined aminonitrile-oxazolidines with a Grignard reagent. Tetrahedron Letters, 1999, 40 (29), pp.5309-5313. 10.1016/S0040-4039(99)00980-6 . hal-03384930

\author{
HAL Id: hal-03384930 \\ https://hal.science/hal-03384930
}

Submitted on 19 Oct 2021

HAL is a multi-disciplinary open access archive for the deposit and dissemination of scientific research documents, whether they are published or not. The documents may come from teaching and research institutions in France or abroad, or from public or private research centers.
L'archive ouverte pluridisciplinaire HAL, est destinée au dépôt et à la diffusion de documents scientifiques de niveau recherche, publiés ou non, émanant des établissements d'enseignement et de recherche français ou étrangers, des laboratoires publics ou privés. 


\title{
Substitution and stereochemical effects in the reactions of combined aminonitrile-oxazolidines with a Grignard reagent
}

\author{
Marc Le Bail, Joëlle Pérard, David J. Aitken * and Henri-Philippe Husson \\ Laboratoire de Chimie Thérapeutique associé au CNRS, Faculté des Sciences Pharmaceutiques et Biologiques, Université \\ René Descartes, 4 Avenue de l'Observatoire, 75270 Paris cedex 06, France
}

\begin{abstract}
A study of the reaction of phenyl magnesium bromide with various $N$-(cyanomethyl)oxazolidines showed that product formation (essentially 3 -imidazolines and 2-aminomorpholines) is highly sensitive to the substitution pattern and stereochemistry, and appears to involve initial complexation of the Grignard reagent to ring-oxygen. (C) 1999 Published by Elsevier Science Ltd. All rights reserved.
\end{abstract}

Keywords: aminonitriles; oxazolidines; Grignard reactions.

Recently, ${ }^{1}$ we described the first detailed study of the reactions of organometallic reagents with a representative combined aminonitrile-oxazolidine system, namely $(R)-N$-cyanomethyl-4-phenyloxazolidine 1. Two unusual heterocyclic structures, 3 -imidazolines 2 and 2 -aminomorpholines 3 , were produced in yields which varied with the nature of the organometallic reagent. For Grignard reagents, the general trend was towards the formation of 2 as the major product and 3 as the minor; an imine anion $\mathbf{A}$, the result of initial nucleophilic attack of the nitrile centre, was suggested as the common intermediate for both products in a competitive process (Scheme 1).<smiles>N#CCN1CCC[C@H]1P</smiles><smiles></smiles><smiles>[R]CN1C[C@]([R])(N)OC[C@H]1c1ccccc1</smiles>

Scheme 1 .

With a view to investigating the scope of the reaction and in the hope of gaining more information concerning mechanistic aspects, we decided to study the effects of substitution at the nitrile $\alpha$-carbon

\footnotetext{
* Corresponding author. Present address: Laboratoire SEESIB-CNRS, Département de Chimie, Université Blaise Pascal Clermont-Ferrand II, 24 avenue de Landais, 63177 Aubière cedex.

Fax: 04734077 17; e-mail: aitken@chisg1.univ-bpclermont.fr
} 
Table 1

Products 2 and 3 obtained in reactions of various aminonitrile-oxazolidines 1, 4,5 and 6 with $\mathrm{PhMgBr}$

\begin{tabular}{|c|c|c|c|c|c|c|c|c|c|c|c|c|c|}
\hline \multirow{2}{*}{$\frac{\text { Substrate }^{2}}{1}$} & \multirow{2}{*}{$\frac{\mathrm{R}^{1}}{\mathrm{H}}$} & \multirow{2}{*}{$\frac{\mathrm{R}^{2}}{\mathrm{H}}$} & \multicolumn{2}{|c|}{$2(\%)^{b}$} & \multicolumn{2}{|c|}{$3(\%)^{b, c}$} & \multicolumn{2}{|c|}{ Substrate" } & \multirow{2}{*}{$\frac{\mathrm{R}^{1}}{\mathrm{Me}}$} & \multirow{2}{*}{$\frac{\mathrm{R}^{2}}{\mathrm{Pr}}$} & \multicolumn{2}{|c|}{$2(\%)^{b}$} & $3(\%)^{b . c}$ \\
\hline & & & $2 a$ & 55 & $3 \mathbf{a}$ & 24 & $(S)$ & $6 a$ & & & - & & - \\
\hline$(S) \mathbf{4 a}$ & $\mathrm{Me}$ & $\mathrm{H}$ & $\overrightarrow{2 b}$ & 50 & $\mathbf{3 b}$ & 15 & $(R)$ & $6 a$ & $\mathrm{Me}$ & $\operatorname{Pr}$ & $2 \mathbf{k}^{d}$ & 54 & $3 k^{d} \quad 6$ \\
\hline (R) $4 \mathrm{a}$ & Me & $\mathbf{H}$ & $2 c$. & 37 & $3 c$ & 25 & $(R S)$ & $6 a$ & $\mathrm{Me}$ & Pr & $21^{d}$ & 26 & - \\
\hline (S) $4 \mathrm{~b}$ & Pr & $\mathbf{H}$ & $2 d$ & 44 & 3d & 6 & $(S)$ & $6 \mathbf{b}$ & $\mathrm{Bn}$ & $\operatorname{Pr}$ & - & & - \\
\hline (R) $4 \mathrm{~b}$ & $\operatorname{Pr}$ & $\mathbf{H}$ & $2 f$ & 40 & $3 f$ & 27 & $(R)$ & $6 \mathbf{b}$ & $\mathrm{Bn}$ & Pr & $2 m$ & 35 & - \\
\hline$(S)$ 4c & Bn & $\mathrm{H}$ & $2 g$ & 35 & $3 g$ & 12 & $(S)$ & $6 c$ & $\operatorname{Pr}$ & $\mathrm{Pr}$ & - & & - \\
\hline $5 a$ & $\mathrm{H}$ & $\mathrm{Me}$ & $2 h^{d}$ & 32 & $3 h^{\circ}$ & 37 & (R) & $6 c$ & $\operatorname{Pr}$ & $\mathrm{Pr}$ & $2 n^{d}$ & 45 & - \\
\hline $5 b$ & $\mathbf{H}$ & $\operatorname{Pr}$ & $2 i^{d}$ & 33 & $3 i^{d}$ & 35 & (S) & 6d & $-\mathrm{CH}_{2} \mathrm{CH}$ & $\mathrm{I}_{2} \mathrm{CH}_{2}-$ & & 50 & - \\
\hline $5 c$ & $\mathbf{H}$ & $\mathrm{Ph}$ & $2 j^{d}$ & 28 & $3 j^{d}$ & 41 & & & & & & & \\
\hline
\end{tabular}

The configuration of the aminonitrile $\alpha$-carbon is noted in parentheses (when appropriate).

'Single stereomers were obtained, notably with retention of configuration at the carbon centre bearing $\mathbf{R}^{1}$ (when appropriate), unless otherwise indicated.

'All compounds have an axial amino group at $\mathrm{C} 2$.

dMixture of epimers $(1: 1)$ at the carbon centre bearing $R^{2}$.

and the oxazolidine $\mathrm{C} 2$. Indeed, it seemed likely that the course of the reaction should depend on the relative electrophilicity of the two reactive centres, which in turn should be dependent on the degree of substitution. Specifically, substitution at the $\alpha$-carbon might be expected to encourage exocyclic iminium formation leading to a Bruylants reaction (thus diminishing attack at the nitrile), while oxazolidine C2 substituent should enhance the favourability of iminium formation on the aminoether side and perhaps induce initial nucleophilic attack at this site (leading to greater yields of 3). ${ }^{\dagger}$ The different substrates 4-6 selected for this study were prepared by standard methods or adaptations thereof. ${ }^{2-5}$ All compounds 5 and 6 were obtained with a 2,4-cis oxazolidine ring substitution pattern.

\section{Results}

Each substrate was treated under standard conditions $\left(\mathrm{N}_{2}\right.$ atmosphere, $\mathrm{Et}_{2} \mathrm{O}$ solution, $-70^{\circ} \mathrm{C}$ to $20^{\circ} \mathrm{C}$, $18 \mathrm{~h}$ ) with a suitable representative Grignard reagent, $\mathrm{PhMgBr}$ (2 equivalents). After work-up, products were isolated by chromatography and characterized. ${ }^{\ddagger}$ Results are presented in Table 1 and summarized in Scheme 2.<smiles>[R]C(C#N)N1[C@H]([R2])OC[C@H]1[C@H](C)Br</smiles>

$1,4,5,6$<smiles>[R]c1nc(-c2ccccc2)c([R])n1[C@H](CO)c1ccccc1</smiles>

2<smiles>[R2]C(c1ccccc1)N1C([R])[C@@](N)(c2ccccc2)OC[C@H]1c1ccccc1</smiles>

3<smiles>[R]C([PH])N(C([R])c1ccccc1)[C@H](CO)c1ccccc1</smiles>

7

Scheme 2.

\footnotetext{
Further details of the various reaction possibilities of this system can be found in the introduction of our previous paper. ${ }^{1}$

* All new products showed satisfactory spectral and/or analytical data.
} 
The effects of substitution on the aminonitrile moiety were investigated first. Compounds 4 , having an $\alpha$-carbon alkyl substituent, gave similar results to those obtained with the unsubstituted parent structure 1, i.e. an imidazoline 2 was obtained as the major product. While an aminomorpholine 3 was also formed as the minor product, its contribution was noticably lower (6-15\%) when the substrate 4 had an $\alpha S$ configuration than was the case for the $\alpha R$ isomers or for $1(24-27 \%)$. While this stereochemical effect did attract our attention, the principle observation at this stage was that $\alpha$-carbon substitution had no appreciable deleterious effect on imidazoline formation; the alternative Bruylants products 7 were obtained in trace amounts only.

Attention was then turned to the effects of substitution at the oxazolidine ring. Substitution at C2 is known to facilitate ring opening with concomitant iminium formation. It was somewhat surprising, therefore, to observe only a small increase in the 3:2 product ratios obtained with compounds 5 as compared to 1 . Even with a strongly stabilizing phenyl substituent, $5 \mathrm{c}$ reacted with the Grignard reagent to give a 3:2 product mixture with a ratio of less than 1.5 to 1 ; clearly, initial iminium formation (which would lead exclusively to 3$)^{1}$ was still not operating with these substituted derivatives.

The stage was set for the study of the cumulative effects of these substitutions, using compounds 6 . The results, however, were quite unexpected. Firstly, aminomorpholine 3 formation was totally suppressed: in only one case, starting from $(\alpha R)-6 \mathbf{a}$, was derivative $3 \mathbf{k}$ observed in very minor quantities. Thus, the simple introduction of an $\alpha$-methyl substituent onto $5 \mathrm{~b}$, giving $6 \mathrm{a}$, provokes a drop in aminomorpholine formation in the reaction with $\mathrm{PhMgBr}$ from $35 \%$ (the major product) to effectively nil. Secondly, a remarkable stereochemical effect originating from the configuration at the $\alpha$-carbon was operating. This phenomenon was not easy to demonstrate: the $\alpha R$ and $\alpha S$ diastereomers of compounds 6 were separated only after repeated chromatography. The $\alpha S$ isomer of $6 \mathrm{a}$ did not react at all with $\mathrm{PhMgBr}$, and was recovered from the reaction, whereas the $\alpha R$ isomer gave over $50 \%$ of imidazoline $2 \mathrm{k}$, one of the highest yields observed so far for imidazoline formation. Furthermore, a 1:1 diastereomeric mixture of $6 \mathbf{a}$ was transformed to exactly half this extent and the product $2 \mathbf{k}$ was obtained with only an $R$ configuration at the imidazoline $\mathrm{C} 5$, thus indicating that only the $R$ isomer of $6 \mathrm{a}$ mixture had reacted. Similarly, in the reaction of $\mathrm{PhMgBr}$ with $(\alpha R)$ - $6 \mathrm{~b}$, imidazoline $2 \mathrm{~m}$ was obtained with only one configuration at $\mathrm{C5}$, while $(\alpha S)-6 \mathbf{b}$ did not react at all. Respecting the trend, $(\alpha R)-6 \mathbf{c}$ gave $2 \mathrm{n}$ as the only product in relatively high yield, while $(\alpha S)-6 \mathrm{c}$ did not react. Finally, the special case of the cyclic doubly-substituted system 6d, which has an $\alpha S$ configuration, ${ }^{\S}$ gave a single product 20 , also in good yield (50\%).

\section{Discussion}

Collectively, these observations can be explained in terms of a complex but well-defined series of events, which in turn highlight the particular reactivity of the combined aminonitrile-oxazolidine system. The first interaction is the association of the Grignard reagent with the oxygen atom of the heterocycle giving $\mathbf{B}$ (Scheme 3). However, in contrast with simple oxazolidines ${ }^{6-12}$ and other $\alpha$-aminoether systems, ${ }^{13-15}$ this interaction is not sufficient to induce iminium formation (even with a $C 2$ substituent present), because the nitrogen lone pair is partially retained in the potential iminium represented by the $\alpha$-aminonitrile moiety. Nonetheless, development of this exocyclic iminum is insufficient for promotion of a Bruylants reaction, even when the $\alpha$-carbon is substituted, in contrast to the usual reactivity of $\alpha$-aminonitriles. ${ }^{16,17}$ Thus the only way for the complex $B$ to evolve is by addition across the face of the heterocycle to the appropriately positioned nitrile group to give $\mathbf{A}$. In this intermediate the nitrogen

\footnotetext{
$\$$ This is the only stereoisomer of $6 \mathrm{~d}$ available; other forms are rapidly equilibrated to this most stable configuration. ${ }^{5}$
} 
lone pair is now available for iminium formation which occurs spontaneously giving $\mathbf{C}$. This iminium is now set up for competitive intramolecular nucleophilic attack by either the imine anion, leading to 2 , or a second phenyl group, leading to 3 . The complex factors - substituent, conformational and stereochemical - which determine the relative ease of formation of 2 and 3 from $\mathbf{C}$ are beyond the scope of this study; however, it does seem likely that the iminium character in $\mathbf{C}$ is well-advanced and its formation is non-stereoselective, since the carbon centre derived from the oxazolidine C2 in products 2 and 3 was totally epimerized."

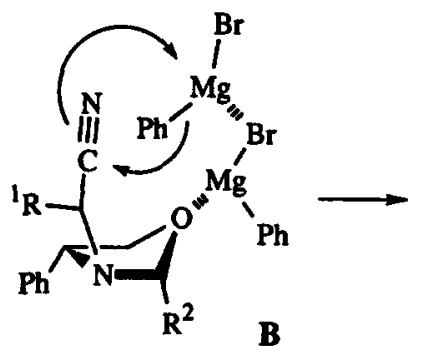

B

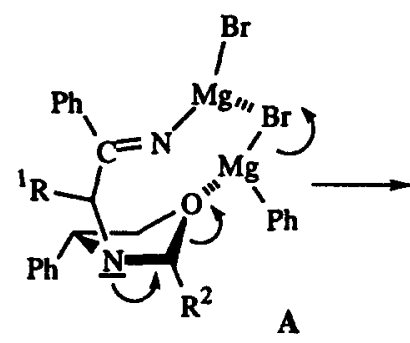

Scheme 3.

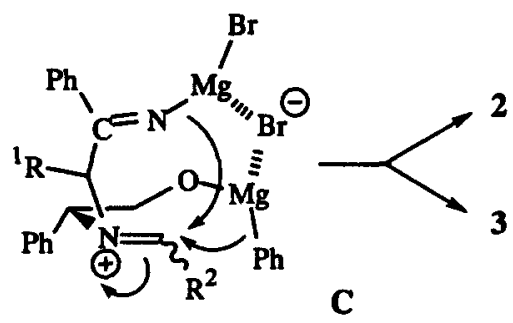

$\mathbf{C}$

The substrate stereoselection observed for compounds 6 warranted further explanation. If the above mechanistic hypothesis is correct, then the nitrile must be accessible to the oxygen-bound Grignard before any reaction can commence. To obtain some indication on the conformational preferences of 6a, each stereoisomer was studied by ${ }^{1} \mathrm{H}$ NMR spectroscopy for nuclear Overhauser effects (n.O.e.). For the $\alpha R$ isomer, an n.O.e. was observed between $\mathrm{H} \alpha$ and $\mathrm{H} 2$ while no effect was observed for the methyl group. This suggests an accessible endo-nitrile conformation, i.e. facilitating addition of a phenyl group (Fig. 1). In contrast, the $\alpha S$ isomer displayed an n.O.e. between $\mathrm{H} 2$ and both $\mathrm{H} \alpha$ and the $\alpha$-methyl group; this indicates a conformation in which the nitrile cannot react with the complexed Grignard. While the origins of these conformational preferences are not clear, their existence explains the striking difference in reactivity. The stereoselection effect is much reduced in the reactions of compounds 4 , because the lower face of the heterocycle is less sterically hindered. 3,4-cis Configurations are thus accessible $^{3}$ and presumably allow underside complexation and reaction of the Grignard, which means that both stereoisomers of 4 can react. In the case of $(\alpha S)-6 \mathrm{~d}$, constraints imposed by the piperidine ring force the $\alpha$-carbon to present the nitrile axially ${ }^{17}$ where it is ideally positioned for attack by the complexed Grignard reagent.

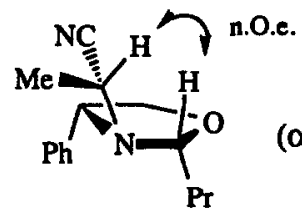

$(\alpha R)-6 \mathrm{a}$

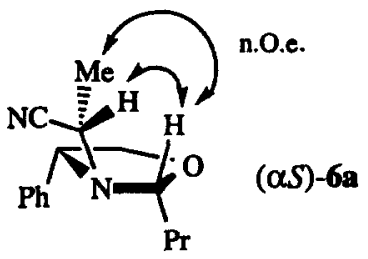

Figure 1.

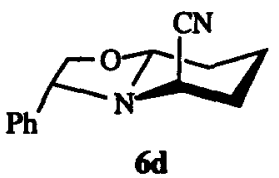

$6 d$

\footnotetext{
I High diastereomeric excesses have been reported in the addition of Grignard reagents to chiral C2-substituted oxazolidines having bulky $\mathrm{N} 3$ substituents. ${ }^{10,11}$ However, with an $N$-methyl substituent (comparable with our $N$-cyanomethyl substituent) the stereoselectivity is in fact poor. ${ }^{7,18}$
} 


\section{Conclusion}

This study demonstrates that combined aminonitrile-oxazolidine systems possess a reactivity profile which is typical of neither aminonitriles nor oxazolidines alone. We interpret the results in terms of a diminished potential iminium nature for both these types of function, since each is competing with the other for the participation of the nitrogen lone pair, resulting in suppression of both Bruylants and direct ring opening reactions. Nonetheless, reactions may occur via an initial adduct of type A, following specific paths which are dependent on stereochemical and conformational factors and which will merit more detailed study.

\section{Acknowledgements}

M.L.B. thanks CNRS and Rhône-Poulenc-Rorer for a grant awarded through the BioAvenir programme.

\section{References}

1. Le Bail, M.; Pérard, J.; Aitken, D. J.; Bonin, M.; Husson, H.-P. Tetrahedron Lett. 1997, 38, 7177-7180.

2. Marco, J. L.; Royer, J.; Husson, H.-P. Tetrahedron Lett. 1985, 26, 3567-3570.

3. Besson, L.; Le Bail, M.; Aitken, D. J.; Husson, H.-P.; Rose-Munch, F.; Rose, E. Tetrahedron Lett. 1996, 37, 3307-3308.

4. Arséniyadis, S.; Huang, P. Q.; Morellet, N.; Beloeil, J.-C.; Husson, H.-P. Heterocycles 1990, 31, 1789-1799.

5. Bonin, M.; Grierson, D. S.; Royer, J.; Husson, H.-P. Org. Synth. 1992, 70, 54-59.

6. Takahashi, H.; Suzuki, Y.; Kametani, T. Heterocycles 1983, 20, 607-610.

7. Takahashi, H.; Niwa, H.; Higashiyama, K. Heterocycles 1988, 27, $2099-2102$.

8. Takahashi, H.; Hseih, B. C.; Higashiyama, K. Chem. Pharm. Bull. 1990, 38, 2429-2434.

9. Higashiyama, K.; Inoue, H.; Takahashi, H. Tetrahedron 1994, 50, 1083-1092.

10. Yamauchi, H.; Takahashi, H.; Higashiyama, K. Chem. Pharm. Bull. 1998, 46, 384-389.

11. Poerwono, H.; Higashiyama, K.; Takahashi, H. J. Org. Chem. 1998, 63, 2711-2714.

12. Yamauchi, T.; Takahashi, H.; Higashiyama, K. Heterocycles 1998, 48, 1813-1823.

13. Andres, C.; Nieto, J.; Pedrosa, R.; Villamañán, N. J. Org. Chem. 1996, 61, 4130-4135.

14. Bortolussi, M.; Cinquin, C.; Bloch, R. Tetrahedron Lett. 1996, 37, 8729-8732.

15. Pandey, G.; Reddy, P. Y.; Das, P. Tetrahedron Letr. 1996, 37, 3175-3178.

16. Shafran, Y. M.; Bakulev, V. A.; Moknushin, V. S. Russ. Chem. Rev. 1989, 58, 148-162 and references cited therein.

17. Husson, H.-P.; Royer, J. Advances in the Use of Synthons in Organic Chemistry; Dondoni, A., Ed.; JAI Press: Greenwich, 1995; Vol. 2, pp. $1-68$ and references cited therein.

18. Wu, M.-J.; Pridgen, L. N. J. Org. Chem. 1991, 56, 1340-1344. 